\title{
CORRECTIONS
}

\section{Author Correction: Regulation of transposable elements by DNA modifications}

Özgen Deniz (iD, Jennifer M. Frost (iD) and Miguel R. Branco (D)

Nature Reviews Genetics (2019) https://doi.org/10.1038/s41576-019-0106-6

Published online 12 March 2019

The originally published article contained an error in Figure 2a: for the left side of the figure part (showing piRNA-directed DNA methylation of mouse transposable elements), DNMT3A/B should have been DNMT3C. The article has now been corrected online.

https://doi.org/10.1038/s41576-019-0117-3 I Published online 20 March 2019 